\title{
http://bjas.journals.ekb.eg \\ Radiographic Risk Factors for Predicting Failure of Geriatric Intertrochanteric Fracture Treatment with Proximal Femoral Nail
}

S.M.Zahid, M.M.Abou-Zied and M.S.Abo-mosalam

Orthopedic Surgery Dept., Faculty of Medicine, Benha Univ., Benha, Egypt

E-Mail:Mohamed255@gmail.com

\begin{abstract}
The proximal femoral nail is the most common device used to treat unstable intertrochanteric fractures (ITFs) (AO/OTA 31-A2 and A3) in the geriatric population. However, there is lack of radiological parameter to evaluate the entry point; hence, this study reports a new radiological parameter to evaluate the entry point of the nail. Besides, other risk factors were also examined. The series included 20 cases treated with proximal femoral nail. Those patients were emulated dependent upon clinically What's more radiologically with pelvic anteroposterior Furthermore hip parallel perspectives during 4weeks ,8weeks, 3 months, 6 months postoperatively. Demographic data, radiological parameters, and side-difference of the separation from those piriformis fossa of the more terrific trochanteric tubercle in the anteroposterior perspective (dPG) were compared the middle of the union Furthermore disappointment gatherings. Student's $t$ test, $\chi 2$ test, and different logistic relapse were utilized within those measurable analyses. Normal agdistis may be 63 . The etiology of the fractures might have been 4 RTA patients (20\%) Also 16 tumbling patients. The AO/OTA arrangement framework might have been utilized. There were 9 sort 31-A2 fractures (45\%), this ponder exhibited that $\mathrm{TAD}>24 \mathrm{~mm}, \mathrm{DPG}>7 \mathrm{~mm}$ expanded those danger about disappointment after nailing Previously, flimsy intertrochanteric fractures, and it might have been An critical predictor from claiming disappointment. This recommended another radiological parameter, DPG will reflect the geometry of the more excellent trochanter following nailing, we discovered that expanded DPG will be connected with expanded danger from claiming disappointment. This ponder gives extra confirmation demonstrating that sex and tad have huge impacts on the results about flimsy ITFs following nailing. Moreover, the recently news person radiological parameter, dPG, could be used to anticipate those disappointment for ITFs approached utilizing proximal femoral nails.
\end{abstract}

Keywords: Intertrochanteric fracture, Proximal femoral nail, Geriatric.

\section{Introduction}

Intertrochanteric (IT) fractures of the femur would regular clinched alongside elderly people with osteoporotic bones Also frequently the outcome from claiming minor provincial tumbles. Osteoporosis coupled for a propensity with fall may be answerable for secondary occurrence for hip fractures toward this agdistis. Future will be relentlessly expanding overall Furthermore this done turn, builds those geriatric populace and the hip fractures. Inability habitually effects from constant ache Also constrained physical portability over hip fractures What's more will be connected with significant horribleness and mortal sin. To the human services framework Furthermore on pop culture Previously, general, intertrochanteric fractures speaks to an plague ailment. An ordinary tolerant with hip crack will be portrayed Eventually Tom's perusing of age age, extreme osteoporosis Also noteworthy co-morbid illnesses [1].

Preservationist medication of the crack for skeletal traction, which used to be those standard to prior parts from claiming twentieth century, which includes prolonged restriction should cot. This sort for medication often brought about systemic Furthermore nearby issues in pulmonary Furthermore renal complications, profound vein thrombosis, cot sores, neglect decay of muscles Also bones, and so on. Those horribleness Also mortal sin might have been high. With succeed these issues inner obsession systems need been utilized with finer outcomes, in the later half of the twentieth century. Since then, there need been An enduring change in the inside obsession strategies. In the right on time nineties, sliding hip screw (DHS) got those standard method for obsession for it fractures universe over [2].

In the late nineties, another system in the structure for cephalomedullry obsession might have been acquainted and is discovered will provide for just as beneficial alternately Indeed going preferred comes about. Its utilization for obsession for it fractures rose from 3. $1 \%$ On 1999 with 67\% On 2006 in the produced universe [3].

In spite of the fact that there would a portion obsession systems for example, sliding hip screw What's more intramedullary interlocking devices, nobody certifications outright crack solidness Furthermore finish bone Uni done elderly patients [4].

Unbending internal obsession Also right on time assembly are those magic focuses of the medication. Stable intertrochanteric crack might a chance to be undoubtedly treated by osteosynthesis for predictable handy results, 
inasmuch as the oversaw economy for flimsy intertrochanteric fractures is testing ecause about poor bone quality, osteoporosis Furthermore different underlying illnesses. Osteoporosis Furthermore precariousness are two of the The greater part vital factors prompting unsuitable outcomes of treatment, Also in the elderly the conjunction of unstable, comminuted fractures with osteoporosis worsens the prognosis. Grade point for medicine if a chance to be to perform a surgery that gives those distinct with best chance to early ambulation [5].

Because of helter skelter disappointment rate and difficulties connected with interior fixation, prosthetic substitution cost need been prescribed by exactly creators Concerning illustration grade medication to flimsy intertrochanteric fractures. This system permits initial ambulation, prompt weight bearing and Urges the tolerant will move What's more practice those included limbs, In this way abstains from recumbence and its cohorted difficulties. Those expanded blood loss, mechanical difficulties such as disengagement and the compelling reason for calcar supplanting are conceivable difficulties for arthroplasty [6].

Those point about this investigation will be to assess the clinical results, utilitarian result and difficulties from claiming intramedullary nail in the medication for femoral intertrochanteric fractures.

\section{Patients and methods}

The contemplate might have been carried during El-Helmia military healing facility from january 2018 to december 2019 (date of most recent take after up), prospective instance of arrangement consider to on assess danger figures to disappointment after nailing. The arrangement incorporated 20 cases treated for proximal femoral nail. Those patients were trailed dependent upon clinically Also radiologically with pelvic anteroposterior Furthermore hip parallel sees toward 4weeks ,8weeks, 3 months, 6 months postoperatively.

Incorporation criteria included:. Elderly patient (over 60 years old)

- Males and Females.

- Closed fractures.

- Unstable intertrochanteric fractures.

\section{Exclusion criteria included}

- Open fractures.

- Stable intertrochanteric fractures.

- Younger patient (<60 years old).

- Pathological fracture due to secondaries

- Nonambulation
- previous contralateral or ipsilateral hip orthopedic surgeries

Unstable ITF was defined as an ITF with an insufficient lateral wall, inadequate medial support (involvement of the lesser trochanter), or a reverse oblique fracture line. Unstable ITFs were classified as AO/OTA 31-A2 or 31A3 dependent upon if they were parallel divider fractures or reverse angled fractures, individually. We utilized the proximal femoral nail on treat flimsy ITFs, and the methods were performed Toward a senior inhabitant under supervision of a trauma specialist.

Those ponder holds 20 patients who met the consideration criteria. All patients underwent clinical catch up and radiography for pelvic anteroposterior (AP) and hip parallel perspectives In 4 weeks, 8 weeks, 3 months, Furthermore 6 months then afterward the operation.

Those Conclusion might have been ordered under Uni or disappointment as stated by those last radiological reports. Slack screw cut-out, nonunion, What's more osteonecrosis were characterized as disappointment results.

All patients were evaluated preoperatively using:

- ATLS protocol.

- History taking included; name, age, sex, address, occupation, special habits, cause and the time of injury, and whether it due to fall, direct trauma, motor vehicle accident or pedestrians by motor vehicle. Asking for any previous injuries and previous surgical interventions, any medical co-morbidity and medications.

- Examination; all patients were examined clinically for evaluation of the type of the fracture, whether it is simple or open, whether patient mono or poly traumatized and whether accompanied by any neurological or vascular injury.

- Radiological examination; X-ray AP pelvis and lateral view of the affected hip were carried to demonstrate fracture pattern, fracture stability and comparing the injured hip with the contra lateral normal side. The opposite hip could be also inspected to measure the prefracture neck-shaft angle, preoperative planning and templating to choose the appropriate nail diameter and lag screw length.

Reciprocal damage and other pathologic techniques that might impact medication must Additionally make managed out. The parallel perspective may be The greater part supportive over delineating those posterior crack pieces and the sum from claiming posterior uprooting (sag) at those crack transport. 
Patients' demographics including age, sex and side from claiming damage were compared between those Uni What's more disappointment gatherings. Radiological parameters including decrease caliber around AP and parallel views, TAD, Furthermore AO/OTA order were also compared the middle of those aggregations. Clinched alongside addition, the recently suggested radiological parameter dPG might have been assessed for its unwavering quality What's more its capacity on anticipate disappointment. All radiographs were reviewed independently by two orthopedic trauma surgeons

- Routine preoperative labs; including blood grouping and cross matching Physician consultation; for medical co-morbidities for evaluation and management.

\subsection{Statistical analysis}

Data management and statistical analysis were done using SPSS vs.25. (IBM, Armonk, New York, United states). Numerical data was summarized as means and standard deviations. Categorical data was summarized as numbers and percentages. Comparisons between study groups were done using Kruskal Wallis test for numerical data. Pairwise analysis was done in case of significant overall effect. All pairwise were Bonferroni adjusted. Categorical data was compared using Fisher's exact test. P values less than 0.05 were considered significant.

\section{Results}

The study was conducted on 20 patients with unstable intertrochanteric fracture who had proximal femoral nail fixation. The AO/OTA classification was used to grade the fractures. Average age is 63. The etiology of the fractures was 4 RTA patients $(20 \%)$ and 16 falling patients. The AO/OTA classification system was used. There were 9 type $31-\mathrm{A} 2$ fractures (45\%), and 11 type 31-A3 fractures $(55 \%)$. Age, Sex, mode of trauma, fracture type and size are presented in Table (1).

Table (1) Age, Sex, mode of trauma, fracture type and size of studied groups.

\begin{tabular}{|c|c|c|c|c|c|c|c|}
\hline \multirow{3}{*}{ AO classification } & & \multicolumn{4}{|c|}{ Outcome } & \multirow{2}{*}{\multicolumn{2}{|c|}{ test }} \\
\hline & & \multicolumn{2}{|c|}{ Union } & \multicolumn{2}{|c|}{ Failure } & & \\
\hline & & $\mathbf{N}$ & $\%$ & $\mathbf{N}$ & $\%$ & $X^{2}$ or $\mathbf{t}$ & P-value \\
\hline \multirow{2}{*}{ Age } & Range & \multirow{2}{*}{\multicolumn{2}{|c|}{$\begin{array}{c}61-79 \\
70.250 \pm 5.994\end{array}$}} & & 75 & \multirow{2}{*}{$\mathrm{t}=0.310$} & \multirow{2}{*}{0.760} \\
\hline & Mean \pm SD & & & & \pm 4.500 & & \\
\hline \multirow{2}{*}{ Sex } & Male & 13 & 81.25 & 2 & 50.00 & \multirow{2}{*}{$\mathbf{X}^{2=} 1.667$} & \multirow{2}{*}{0.197} \\
\hline & Female & 3 & 18.75 & 2 & 50.00 & & \\
\hline \multirow{2}{*}{ Fracture type } & $31-\mathrm{A} 2$ & 6 & 37.50 & 3 & 75.00 & \multirow{2}{*}{$\mathbf{X}^{\mathbf{2}=} 1.818$} & \multirow{2}{*}{0.178} \\
\hline & $31-\mathrm{A} 3$ & 10 & 62.50 & 1 & 25.00 & & \\
\hline \multirow{2}{*}{ Fracture side } & Right & 11 & 68.75 & 3 & 75.00 & \multirow{2}{*}{$\mathbf{X}^{2}=0.060$} & \multirow{2}{*}{0.807} \\
\hline & Left & 5 & 31.25 & 1 & 25.00 & & \\
\hline \multirow{2}{*}{ Mode of trauma } & RTA & 4 & 25.00 & 0 & 0.00 & \multirow{2}{*}{$\mathbf{X}^{\mathbf{2}=} 1.250$} & \multirow{2}{*}{0.264} \\
\hline & Falling & 12 & 75.00 & 4 & 100.00 & & \\
\hline
\end{tabular}

In the Union group; there was 7 good reduction (43.7\%), 7 acceptable reduction (43.7\%) and 2 bad reduction (12.5\%). In the failure group; there was 1 good reduction (25\%), 1 acceptable reduction $(25 \%)$ and 2 bad reduction (50\%) Fig (1).

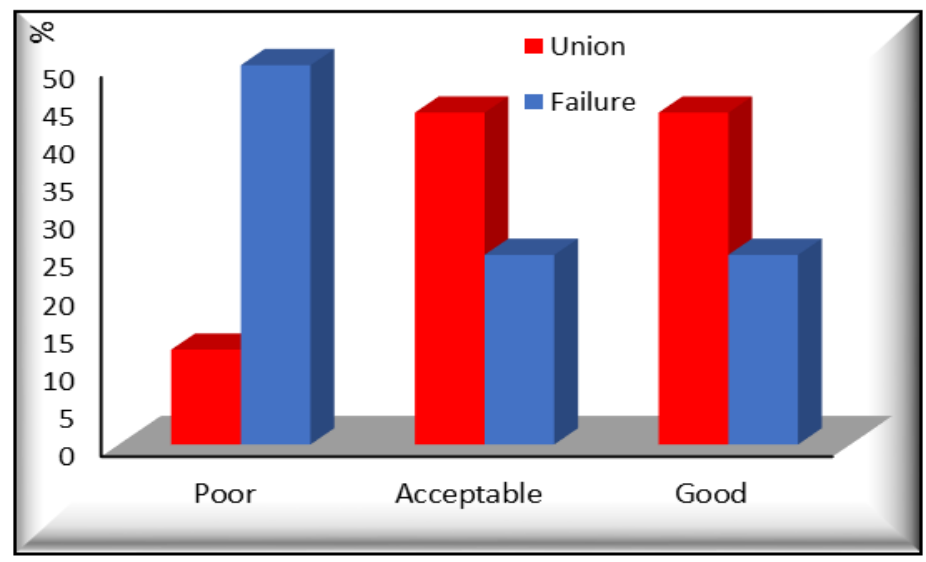

Fig (1) Reduction quality in studied groups 
This study demonstrated that TAD $>24 \mathrm{~mm}$ ,DPG $>7 \mathrm{~mm}$ increased the risk of failure after nailing in unstable intertrochanteric fractures , and it was a significant predictor of failure. This proposed a new radiological parameter, DPG to reflect the geometry of the greater trochanter after nailing, we found that increased DPG is associated with increased risk of failure.

\section{Case presentation}

\section{Case no 1 Fig ( 2-6)}

\section{Patient profile}

Female patient, 72 years old, housewife, was hit by car while crossing the street and she developed right side intertrochanteric fracture. She has irrelevant medical history. She was operated on the $1^{\text {st }}$ day after trauma.

\section{Fracture classification: 31 AO 3.3}

Intraoperative details

1- Incision length: $8 \mathrm{~cm}$

2- Fluoroscopic imaging time: $1.5 \mathrm{~min}$
3- Estimated blood loss: $150 \mathrm{cc}$

4- Operative time: $120 \mathrm{~min}$

5- Difficulties in procedure: lag screw insertion

6- Reaming: yes

\section{Postoperative X-ray evaluation}

1- Point of entry: Tip

2- TAD: $24 \mathrm{~mm}$

3- DPG: $6.6 \mathrm{~mm}$

4- Number of distal locking screw: 2

5- Nail working length: $11.2 \mathrm{~cm}$

6- Medullary filling: $85 \%$

7- Quality of reduction: GOOD

8- Bone quality: GOOD

\section{Postoperative program}

partial weight bearing at the $2^{\text {nd }}$ day after operation. Total hospital stay was 3 days.

Full weight bearing begins at 6 weeks.

Follow up period: 6 months

Postoperative Complications: none

Time to union: 14 week

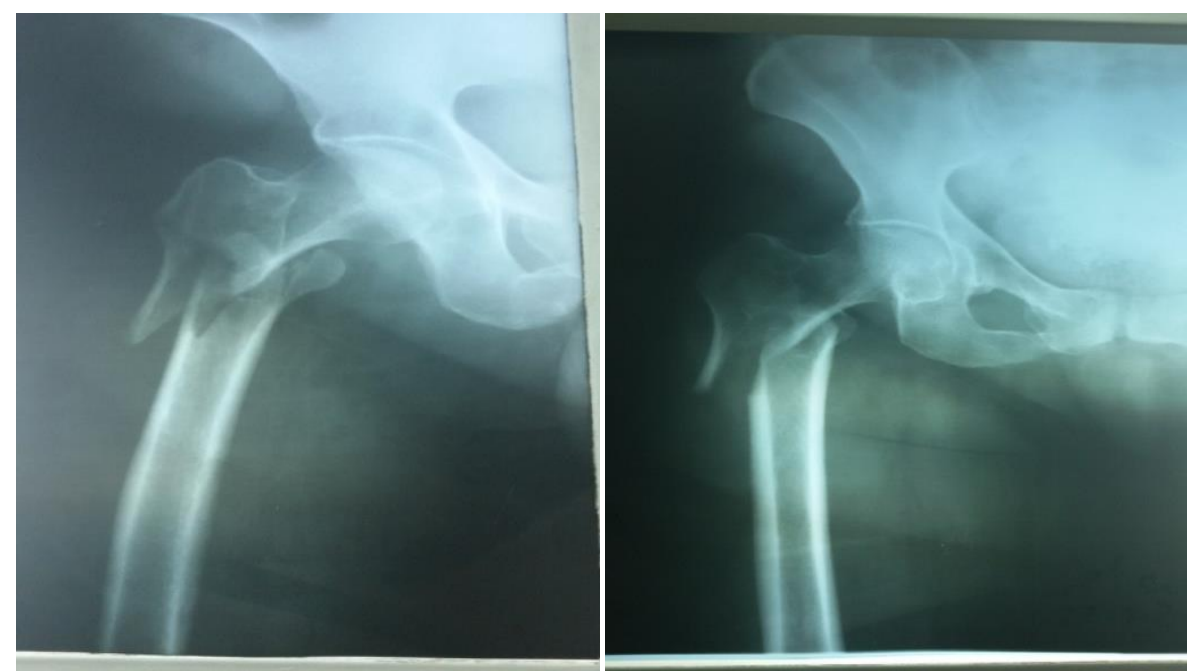

Fig (2) Preoperative X-ray Lateral and AP

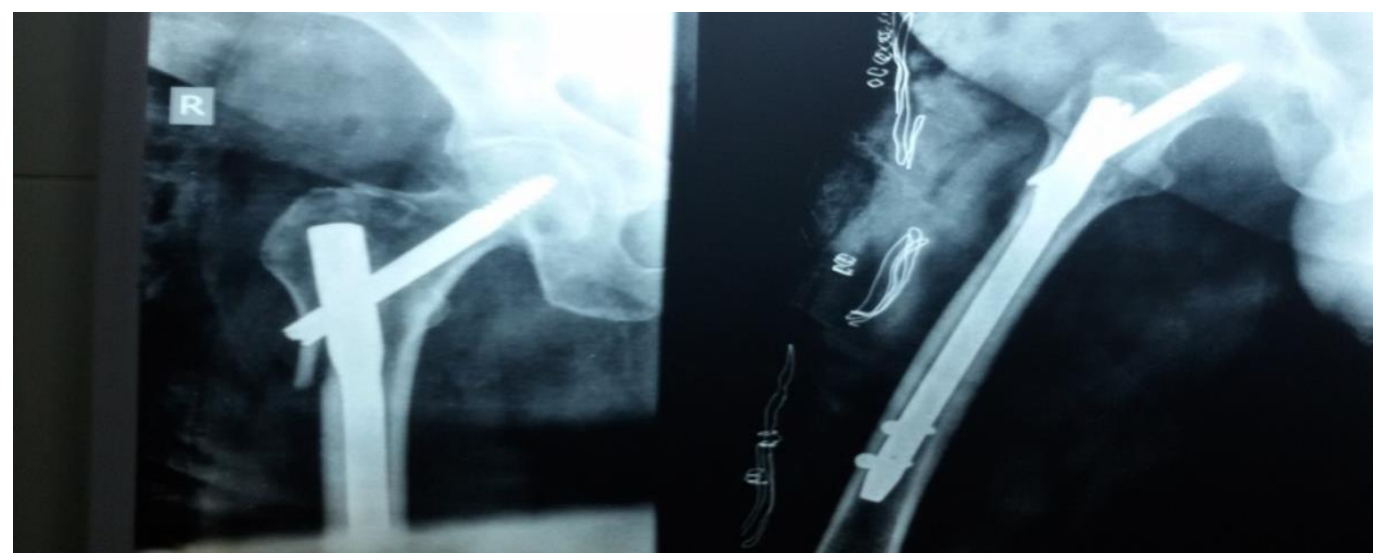

Fig (3) Postoperative X-rays 


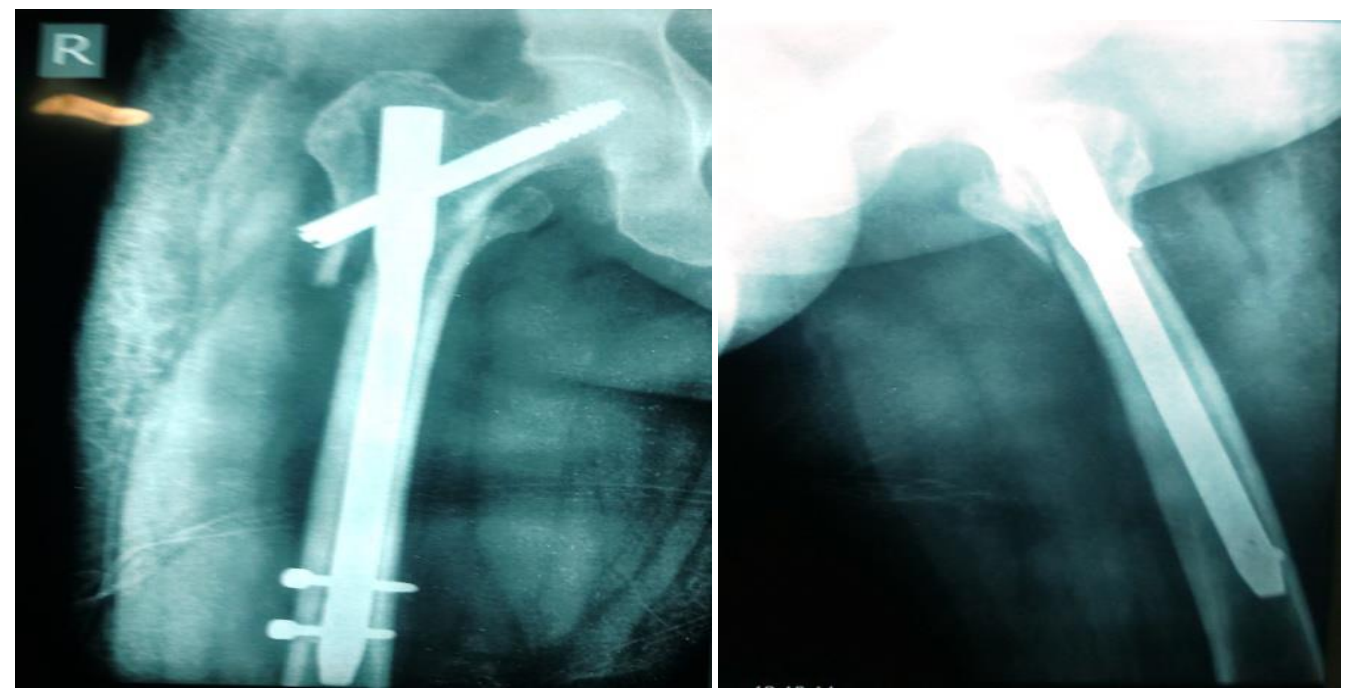

Fig (4) 2 weeks follow up AP-LT views

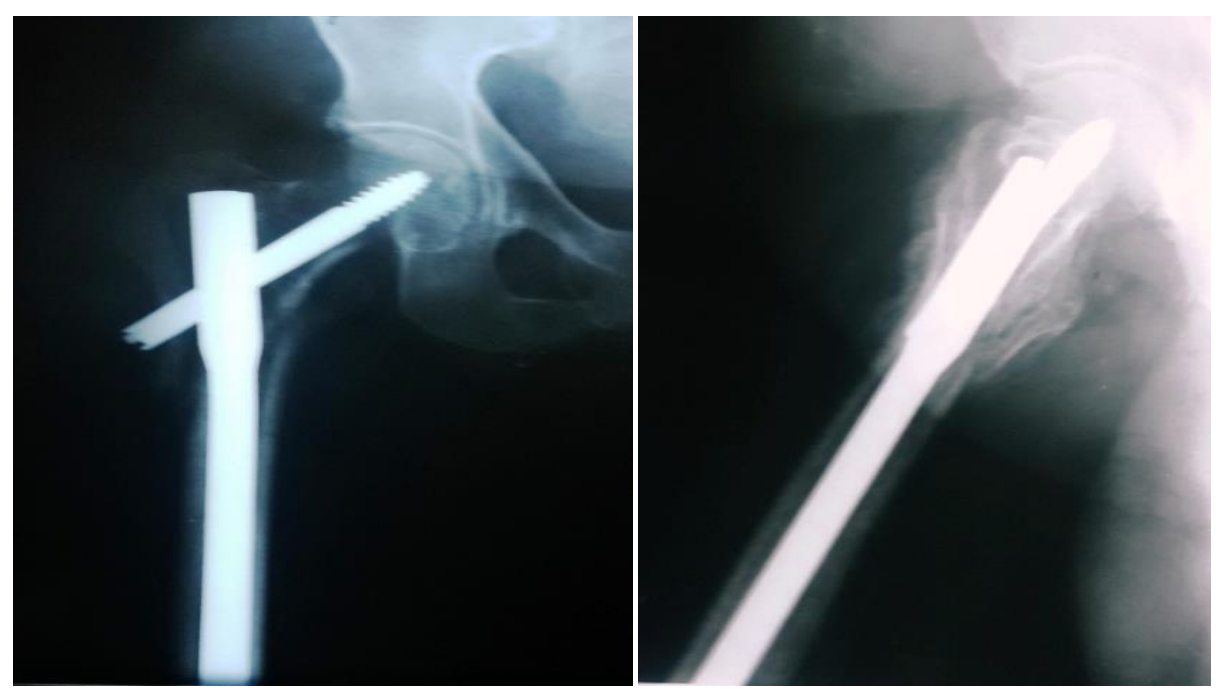

Fig (5) 8 weeks follow up AP-LT views

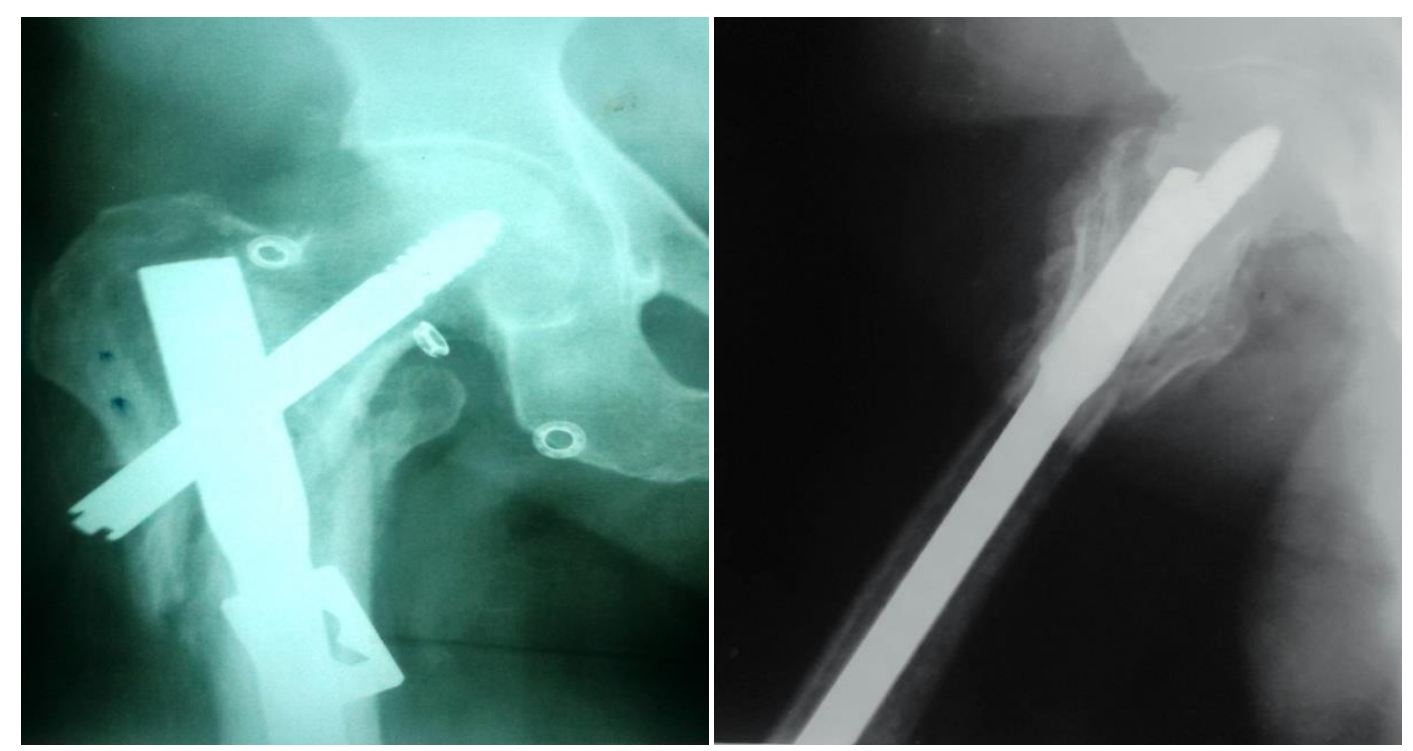

Fig (6) 12 Weeks follow up AP-LT views

Benha Journal Of Applied Sciences, Vol.(5) Issue(4) Part (2) (2020) 
Case no 2 Fig ( 7 \& 8)

Patient profile

Male patient, 75 years old, fell at house and she developed right side intertrochanteric fracture. He is hypertensive controlled by tritace $5 \mathrm{mg}$ and was operated on the $3^{\text {rd }}$ day after trauma.

\section{Fracture classification: 31 AO 1.2}

Intraoperative details

1- Incision length: $8 \mathrm{~cm}$

2- Fluoroscopic imaging time: $1.5 \mathrm{~min}$

3- Estimated blood loss: $200 \mathrm{cc}$

4- Operative time: $114 \mathrm{~min}$

5- Difficulties in procedure: No

6- Reaming: No
Postoperative X-ray evaluation

1- Point of entry: Tip

2- TAD: $18 \mathrm{~mm}$

3- DPG: $7.3 \mathrm{~mm}$

4- Number of distal locking screw: 2 5- Nail working length: $12.6 \mathrm{~cm}$

6- Medullary filling: $80 \%$

7- Quality of reduction: Good

8- Bone quality: Osteoporotic

Postoperative program partial weight bearing at the $2^{\text {nd }}$ day after operation. Total hospital stay was 5 days.

Full weight bearing begins at 6 weeks

Follow up period: 6 months

Postoperative Complications: none

Range of motion score 20 weeks: 4

Time to union: 16 weeks

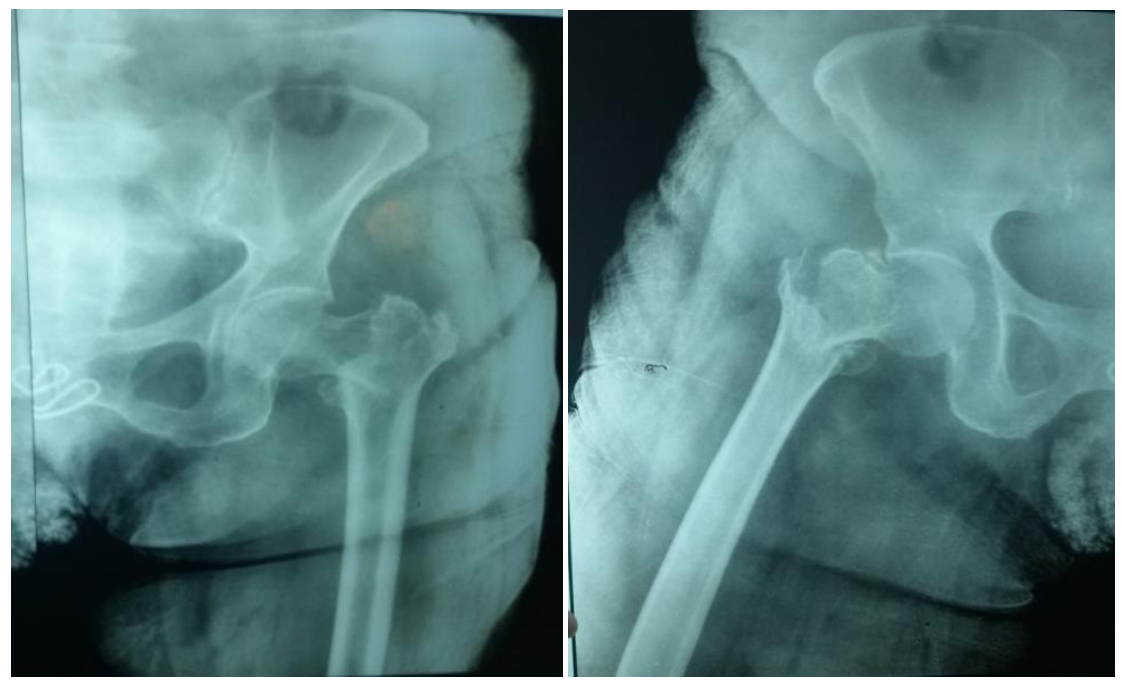

Fig (7) Preoperative x-rays
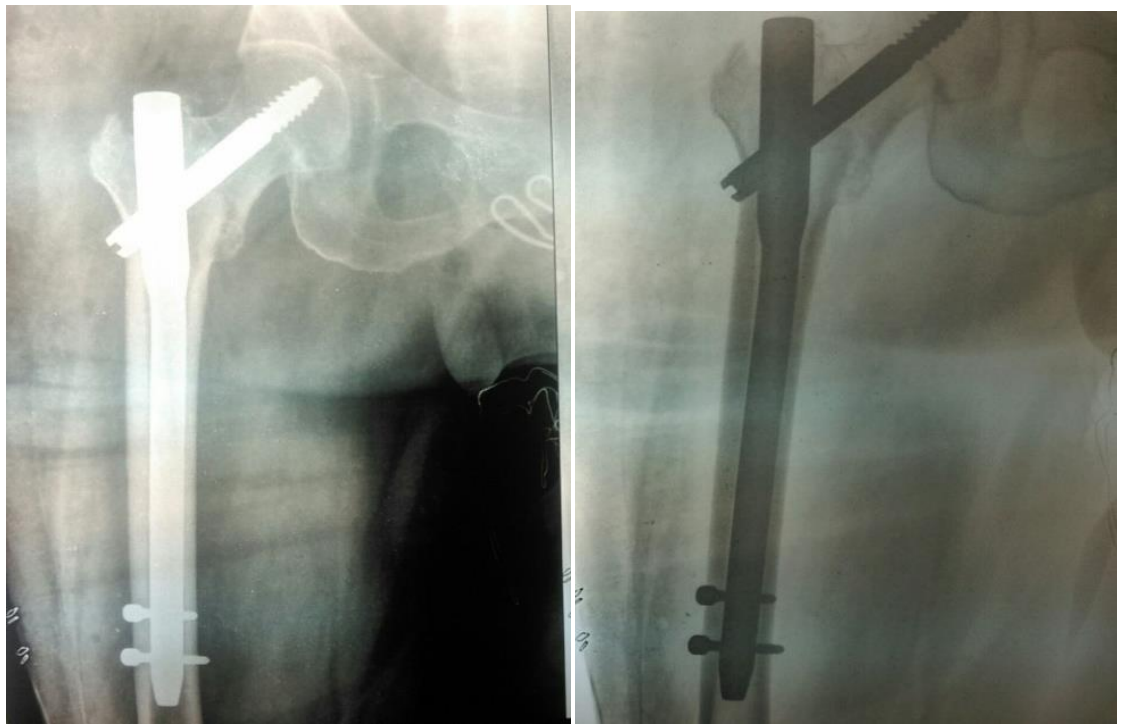

Fig (8) Postoperative x-rays 


\section{Discussion}

This contemplate exhibited that TAD $>24 \mathrm{~mm}$, DPG $>7 \mathrm{~mm}$ expanded those danger from claiming disappointment after nailing On flimsy intertrochanteric fractures , and it might have been a huge predictor about disappointment. This recommended another radiological parameter, DPG will reflect the geometry of the more amazing trochanter following nailing, we found that expanded DPG will be connected with expanded hazard for disappointment.

An comparable perceptions were reportedby Hsu Also partners [7], exhibited that female sex, tad $>25 \mathrm{~mm}$, What's more $\mathrm{dPG}>6 \mathrm{~mm}$ expanded the hazard of disappointment after nailing done flimsy ITF. Additionally, dPG might have been a dependable measurement, Also it might have been a huge predictor for disappointment.

In spite of gathered confirmation presently prescribes no distinction to result for flimsy fractures treated for whichever those DHS or cephalomedullary nail, those cephalomedullary nail may be viewed as invaluable Previously, keeping anatolian dialect deformities. [8], a greater amount recently, utilization of those cephalomedullary nail need ended up basic over clinical act to treating flimsy ITFs. From 1999 should 2006, those use rate of the intramedullary nail need been reportedly expanded starting with $3 \%$ will $67 \%$. [9]. Those disappointment example about sliding hip screws Also their danger figures have been great studied; [10] however, the disappointment design of the cephalomedullary nail What's more danger figures about disappointment necessity further investigation. A past ponder showed that those The majority average disappointment example connected with the intramedullary nail is varus transform of the decrease Also cut-out of the screw [11]. In our study, we Additionally exhibited this disappointment example.

Sex might have been a hazard figure for disappointment for ITFs dealt with utilizing cephalomedullary nails in the current examine and the discovering might have been reliable with the past investigation. [12] we think that those generally more awful osteoporosis Also little bone structural engineering for ladies for our ponder might demonstrate this discovering.

A 31-A3 crack as stated by the AO/OTA arrangement need been perceived Concerning illustration An hazard component to poor conclusions when those sliding hip screw will be utilized Concerning illustration treatment, [13] inasmuch as this hazard will be low At a intramedullary gadget may be utilized Similarly as medicine [14]. In the present study, we watched those wonder in univariate examination. Those cephalomedullary nail gives firm parallel support, which Might need kept uprooting over 31-A3 fractures and, hence, diminishing the hazard about disappointment done our study.

Numerous investigations have showed that tad might not just influence the disappointment rate from claiming DHS However it is Additionally a huge predictor from claiming conclusions then afterward intramedullary nailing. [15] in the available study, we also watched that tad is An solid predictor for failure, which includes of the existing confirmation.

\section{Conclusion}

This study proposed a new radiological parameter, dPG, to reflect the geometry of the greater trochanter after nailing. We found that increased dPG is highly associated with failure and indicates varus change of the proximal fragment or lateralization of the distal fragment, which is closely related to entry point selection and canal preparation.

\section{References}

[1] K. J. Koval and J. D. Zuckerman, "Hip fractures: II. Evaluation and treatment of intertrochanteric fractures," JAAOSJournal Am. Acad. Orthop. Surg; Vol. 2(3), PP. 150-156, 1994.

[2] S. H. Bridle, A. D. Patel, M. Bircher, and P.T.Calvert, "Fixation of intertrochanteric fractures of the femur. A randomised prospective comparison of the gamma nail and the dynamic hip screw," J. Bone Joint Surg. Br; Vol. 73(2), PP. 330-334, 1991.

[3] P. Dousa, J. Bartonicek, D. Jehlicka, and J. Skala-Rosenbaum, "Osteosynthesis of trochanteric fractures using proximal femoral nails," Acta Chir. Orthop. Traumatol. Cech; Vol. 69 (1),PP. 22-30, 2002.

[4] S. Nuber, T. Schönweiss, and A. Rüter, "Stabilisation of unstable trochanteric femoral fractures. Dynamic hip screw (DHS) with trochanteric stabilisation plate vs. proximal femur nail (PFN)," Unfallchirurg; Vol. 106 (1), PP. 39-47, 2003.

[5] R. Marks, J. P. Allegrante, C. R. MacKenzie, and J. M. Lane, "Hip fractures among the elderly: causes, consequences and control," Ageing Res. Rev; Vol. 2 (1), PP. 57-93, 2003.

[6] K. Sinno, M. Sakr, J. Girard, and H. Khatib, "The effectiveness of primary bipolar arthroplasty in treatment of 
unstable intertrochanteric fractures in elderly patients," N. Am. J. Med. Sci; Vol. 2 (12), P. 561, 2010.

[7] K.-H. Hsu, C.-H. Chang, Y.-P. Su, and M.-C. Chang, "Radiographic risk factors for predicting failure of geriatric intertrochanteric fracture treatment with a cephalomedullary nail," J. Chinese Med. Assoc; Vol. 82 (7), PP. 584-588, 2019.

[8] T. M. Barton, R. Gleeson, C. Topliss, R. Greenwood, W. J. Harries, and T. J. S. Chesser, "A comparison of the long gamma nail with the sliding hip screw for the treatment of AO/OTA 31-A2 fractures of the proximal part of the femur: a prospective randomized trial," JBJS; Vol. 92 (4), PP. 792-798, 2010.

[9] J. O. Anglen, J. N. Weinstein, and A. B. of O. S. R. Committee, "Nail or plate fixation of intertrochanteric hip fractures: changing pattern of practice: a review of the American Board of Orthopaedic Surgery Database," JBJS; Vol. 90 (4), PP. 700-707, 2008.

[10] H. Pervez, M. J. Parker, and S. Vowler, "Prediction of fixation failure after sliding hip screw fixation," Injury; Vol. 35 (10), PP. 994-998, 2004.

[11] A. J. Bojan, C. Beimel, G. Taglang, D. Collin, C. Ekholm, and A. Jönsson, "Critical factors in cut-out complication after Gamma Nail treatment of proximal femoral fractures," BMC Musculoskelet. Disord; Vol. 14 (1), P. 1, 2013.

[12] S.-W. Tsai et al., "Risk factors for cutout failure of Gamma3 nails in treating unstable intertrochanteric fractures: An analysis of 176 patients," J. Chinese Med. Assoc; Vol. 80 (9), PP. 587-594, 2017.

[13] M. J. Parker and H. H. G. Handoll, "Gamma and other cephalocondylic intramedullary nails versus extramedullary implants for extracapsular hip fractures in adults," Cochrane database Syst. Rev; Vol. 5 (9), PP.34-42, 2010.

[14] J. Ito, Y. Takakubo, K. Sasaki, J. Sasaki, K. Owashi, and M. Takagi, "Prevention of excessive postoperative sliding of the short femoral nail in femoral trochanteric fractures," Arch. Orthop. Trauma Surg; Vol. 135 (5), PP. 651-657, 2015.

[15] J. A. Geller, C. Saifi, T. A. Morrison, and W. Macaulay, "Tip-apex distance of intramedullary devices as a predictor of cut-out failure in the treatment of peritrochanteric elderly hip fractures,"
Int. Orthop; Vol. 34 (5), PP. 719-722, 2010. 